\title{
Consumption of ready-to-eat cereals (RTEC) among Malaysian children and association with socio-demographics and nutrient intakes - findings from the MyBreakfast study
}

\author{
Mohd Taib Mohd Nasira, Abdul Razak Nurliyanaa, A. Karim Norimahb, Hamid Jan B. Jan Mohamedc, \\ Sue Yee Tan ${ }^{d}$, Mahenderan Appukuttye, Sinead Hopkins ${ }^{f}$, Frank Thieleckef,g, Moi Kim Ong ${ }^{h}$, Celia Ning ${ }^{h}$ \\ and E. Siong Tee
}

\begin{abstract}
aDepartment of Nutrition and Dietetics, Faculty of Medicine and Health Sciences, Universiti Putra Malaysia, Serdang, Selangor, Malaysia; ${ }^{b}$ Nutritional Science Programme, School of Healthcare Sciences, Faculty of Health Sciences, Universiti Kebangsaan Malaysia, Kuala Lumpur, Malaysia; 'Nutrition Programme, School of Health Sciences, Universiti Sains Malaysia, Kubang Kerian, Kelantan, Malaysia; dDepartment of Nutrition and Dietetics, School of Health Sciences, International Medical University, Malaysia, Kuala Lumpur; ' $S$ ports Science Programme, Faculty of Sports Science and Recreation, Universiti Teknologi MARA, Shah Alam, Selangor, Malaysia; ${ }^{\mathrm{f} C e r e a l ~ P a r t n e r s ~ W o r l d w i d e, ~ L a u s a n n e, ~}$ Switzerland; ${ }^{9}$ 2 Goodness Ltd, Allschwil, Switzerland; 'Nestlé R\&D Center, Singapore; 'Nutrition Society of Malaysia, c/o Division of Human Nutrition, Institute for Medical Research, Kuala Lumpur, Malaysia
\end{abstract}

ABSTRACT

Background: The association between different types of breakfast meals and nutrient intakes has been studied to a lesser extent.

Objective: This study compared nutrient intakes at breakfast and throughout the day between Malaysian children who consumed ready-to-eat cereals (RTEC) and those who did not.

Methods: Anthropometric and dietary data for 1955 children aged 6-12 years from the MyBreakfast study were used in the analysis.

Results: Overall, $18 \%$ of the children consumed RTEC at breakfast on at least one of the recall days. RTEC consumption was associated with younger age, urban areas, higher income and education level of parents. Among consumers, RTEC contributed $10 \%$ and $15 \%$ to daily intakes of calcium and iron respectively and $\geq 20 \%$ to daily intakes of vitamin $C$, thiamin, riboflavin and niacin. RTEC consumers had significantly higher mean intakes of vitamin $C$, thiamin, riboflavin, niacin, calcium, iron and sugar but lower intakes of fat and sodium than non-RTEC consumers at breakfast and for the total day.

Conclusion: Consumption of fortified RTEC at breakfast was associated with lower fat and sodium intakes and higher intakes of several micronutrients both at breakfast and for the total day. However, total sugar intakes appeared to be higher.
ARTICLE HISTORY

Received 22 December 2016 Accepted 24 February 2017

\section{KEYWORDS}

Breakfast foods; ready-to-eat cereals; nutrient intakes; children; Malaysia

\section{Introduction}

Breakfast consumption among children has been associated with higher nutritional adequacy, improved cognitive and academic performance, higher school attendance, and better mood and psychosocial functions compared to breakfast skipping.[1] Furthermore, breakfast consumption has been associated with a lower risk of excess adiposity in both children and adolescents.[2] Children who consume breakfast regularly tend to have higher intakes of total daily energy and key nutrients such as fibre, calcium, vitamins A and C, riboflavin, zinc and iron compared to those who skip breakfast.[1] The nutritional impact of different types of breakfast meals which vary in food and nutrient composition has been studied less than the breakfast occasion . Ready-to-eat cereals (RTEC) are defined as processed cereals that can be eaten without further preparation, and are also known as cold cereals. RTEC can be made of different types of grains including corn, wheat, oats and rice. Oats which need to be cooked before consumption are not considered RTEC. Cornflakes and muesli are the most common types of RTEC that are available in the Malaysian market for the general public.[3] They are generally high in carbohydrate and low in fat. Some RTEC are high in fibre and many are fortified with vitamins and minerals including B vitamins, iron and calcium. Several studies worldwide (in the USA, Europe and Australia) have shown that consumption of RTEC among children and adolescents is associated with higher daily intakes of

CONTACT Mohd Taib Mohd Nasir mnasirmt@upm.edu.my E Department of Nutrition and Dietetics, Faculty of Medicine and Health Sciences, Universiti Putra Malaysia, 43400 UPM Serdang, Selangor, Malaysia

(c) 2017 The Author(s). Published by Informa UK Limited, trading as Taylor \& Francis Group.

This is an Open Access article distributed under the terms of the Creative Commons Attribution License (http://creativecommons.org/licenses/by/4.0/), which permits unrestricted use, distribution, and reproduction in any medium, provided the original work is properly cited. 
energy from carbohydrate, total sugars, dietary fibre and several micro-nutrients (vitamins $\mathrm{A}$ and $\mathrm{D}$, thaimin, riboflavin, niacin, vitamin B6, folate, calcium, iron, magnesium and zinc) and with a lower intake of energy from fat compared to non-consumption. [4] Moreover, consumption of RTEC has also been associated with a greater likelihood of having vitamin and mineral intakes above recommended daily requirements, especially for calcium.[4]

In Malaysia, the traditional breakfast generally includes a rice- or noodle-based hot dish such as fried rice, fried noodles and nasi lemak (rice cooked in coconut milk). A previous study among preschoolers aged 4-6 years in Peninsular Malaysia reported that the most common breakfast foods were bread, rice, noodles, milk and malted beverages.[5] Bread, rice dishes, noodle dishes, sweet and fried traditional cakes and biscuits were found to be the most commonly consumed foods at breakfast among adolescents in Kelantan, Malaysia,[6] while in a rural area in Tuaran, Sabah, the most common breakfast foods among adolescents were fried noodles, fried banana and doughnuts.[7]

RTEC have been available in the Malaysian market since the 1960s yet little is known about the consumption patterns of RTEC at a nationwide level and their contributions to children's daily nutrient intake. Most RTEC are fortified with vitamins and minerals, which can be important contributors to overall nutrient intake of children. The aim of this study, therefore, was to describe the prevalence of RTEC consumption at breakfast in Malaysian children aged 6-12 years according to key socio-demographic characteristics and to compare foods consumed at breakfast and nutrient intake both at breakfast and for the total day between RTEC consumers and non-RTEC consumers.

\section{Materials and methods}

\section{Study design and participants}

Data of 1955 primary school children aged 6-12 years who participated in the MyBreakfast study were used in the present analysis. The MyBreakfast study was a cross-sectional study on breakfast habits of school children in Malaysia. Participants were selected using a multistage sampling method based on geographical location and ethnic group distribution. The sample size was calculated based on the total population of children aged 6-12 years in Malaysia derived from the Population and Housing Census 2010.[8] From this statistic, the percentages of children in the total population in the five regions of Malaysia, including Central, Southern, Northern, East Coast and East
Malaysia, were calculated. Then for each of the regions, the percentages of children in urban and rural areas were determined. The proportion of the main ethnic ethnic groups, namely Malay, Chinese, Indian and Sabah/Sarawak native, in the urban and rural areas of each of the regions were determined. Based on this proportion, a standardized ratio of 1:1 for sex was used to determine the number of boys and girls required for each ethnic groups in the urban and rural area. The details of the sampling procedures are described elsewhere. $[9,10]$ Data collection was carried out in the aforementioned five regions of Malaysia. A total of 33 urban and 12 rural primary schools were randomly selected based on a list of public primary schools in each of the states in Malaysia as of 31 January 2011. For each school, 2-3 classes of Primary 1 to Primary 5 were randomly selected. Children in Primary 6 were not selected in the study because these children were candidates for a national level examination and permission was not granted for these children to involve in the study. Only children who were apparently healthy and with no physical disabilities or learning difficulties were eligible to participate in this study.

Permission to conduct the study was obtained from the Ministry of Education Malaysia and Departments of Education of all the states involved. Ethical approval was obtained from Universiti Kebangsaan Malaysia Research Ethics Committee (UKMREC) and the study was conducted in accordance with the Declaration of Helsinki. A study information sheet was sent to parents together with a standard consent form provided by the UKMREC and a written consent was obtained from the parents. Data collection was conducted from April 2013 to October 2013.

\section{Socio-demographic characteristics}

Data on socio-demographic characteristics including the child's date of birth, sex, ethnicity, parents'education level and monthly household income were obtained from parents through a self-administered questionnaire.

\section{Anthropometric measurements}

Height and weight of the children were measured in schools by trained researchers using standard procedures. Children were asked to empty their pockets and to take off their shoes for the measurements. Height was measured using a SECA stadiometer (SECA 217, Hamburg, Germany) to the nearest $0.1 \mathrm{~cm}$, while weight was measured using a SECA digital weighing scale (SECA Clara 803, Hamburg, Germany) to the 
nearest $0.1 \mathrm{~kg}$. All measurements were taken twice and for each measurement, the mean value was used in the analyses. Body mass index (BMI) was calculated by using the formula BMI = weight $(\mathrm{kg}) /$ height $^{2}(\mathrm{~m})$. Z-scores for BMI-for-age were determined using WHO AnthroPlus Version 1.0.3 software [11] and categorized using WHO Growth Reference 2007.[12] The cut-off points for thinness and severe thinness were $-2 S D$ and $-3 S D$ respectively, while the cut-off points for overweight and obesity were $+1 S D$ and $+2 \mathrm{SD}$ respectively.[12]

\section{Dietary intake}

Food and beverage intakes were assessed on one weekday and one weekend day using a food record for children aged 6-9 years and 24-h dietary recall for respondents aged 10-12 years. Parents completed the food record for children aged 6-9 years with the assistance of an instruction booklet. A brief instruction was also sent to the parents through a text message. Parents were requested to record all foods and beverages consumed by their child over the day and to note the time of consumption. The instruction booklet outlined common household measures to assist parents in the estimation of portion sizes consumed. A food album with pictures of common foods was also provided. Upon return of the dietary records in school, any incomplete food records were sent back to the parents with a short note on the uncompleted part along with a text message.

Meanwhile, a two-day 24-h dietary recall was conducted for children aged 10-12 years in a one-to-one interview by trained researchers in school. Children were requested to recall all the foods and beverages consumed in the past $24 \mathrm{~h}$. Household items such as bowls, dishes, spoons and glasses in commonly used sizes, food models and a food album with pictures of common foods were used to facilitate estimation of portion sizes. For the dietary record and recall, brand information and cooking methods were also recorded where applicable.

Breakfast was defined as the first eating occasion after an overnight sleep until 10 am in the weekdays and $11 \mathrm{am}$ in the weekends. Children who consumed breakfast on at least one of the two recall days were categorized as breakfast eaters, and only these children were included in the analysis. Children who consumed RTEC at breakfast on at least one of the two days were classified as RTEC consumers. Those who did not consume any RTEC at any of the two recall days were categorized as non-RTEC consumers. The mean intake of RTEC for the two recall days were used in the analysis. Mean daily energy and nutrient intakes were analysed using NutritionistPro ${ }^{\mathrm{TM}}$ Software (Axxya Systems LLC, Redmond, WA, USA) based principally on the Malaysian food composition tables.[13] Sugar intake was estimated using manufacturers' labelling as the Malaysian food composition tables do not have information on sugar in its database. Therefore for all non-packaged foods (for example, tea/coffee with condensed milk) including recipes (for example, fried rice and nasi lemak) there was a 0 value for total sugar assigned. Dietary data were also compared to the recommended nutrient intakes (RNI) for Malaysia. [14] An arbitrary cut-off point of $80 \%$ RNI were used to compare the adequacy of the nutrient intake of the children.

Under- and over-reporters of energy intake were determined by the ratio of mean energy intake against basal metabolic rate (BMR). Estimates of BMR for different age groups of participants were calculated using formulas from $\mathrm{FAO} / \mathrm{WHO} / \mathrm{UNU}$ [15] and predictive equations for Malaysian adolescents.[16,17] Under- and over-reporters were identified by using relevant cut-off points.[18] For boys, an under-reporter was defined as having energy intake of less than 1.39 BMR while for girls, an under-reporter was defined as having an energy intake of less than 1.30 BMR. An over-reporter was defined as having energy intake of more than 2.24 BMR for boys and more than 2.10 BMR for girls.[18]

\section{Statistical analyses}

Data were analysed using SPSS software version 19 (IBM Corp., Armonk, NY, USA). The distribution for all variables were checked for normality and non-normally distributed variables were normalized by replacing extreme cases with group mean values. All univariate analyses were conducted using descriptive statistics. The associations between categorical variables and breakfast choice groups were determined using chi-square tests, while the associations between nutrient intakes and breakfast choice groups were determined using analysis of covariates (ANCOVA), controlling for potential confounders including indicators of socio-economic status (SES) and energy intake. The Bonferroni post hoc test was used to determine the differences between groups. The association between the type of breakfast foods consumed and recommended nutrient intake (RNI) achievement by sex and age groups was determined using chi-square tests. Level of significance was determined at $p<0.05$. 


\section{Results}

A total of 5532 primary school children aged 612 years participated in the study, of which 5302 completed two days of 24-h dietary recall. It was estimated that 2648 (52.3\%) of the children under-reported while 421 (8.3\%) over-reported their energy intake. 1993 (39.4\%) were acceptable reporters, among whom 1955 were classified as breakfast consumers (i.e. consumed breakfast on at least one of the two study days) and only these children were included in the analysis of the present paper. Table 1 shows the characteristics of acceptable and unacceptable reporters (under- and over-reporters) who were breakfast consumers. The percentage of acceptable reporters from urban $(40.0 \%)$ and rural $(39.5 \%)$ area was about the same. There was no difference in their family income, and father's and mother's educational level $(p>0.05)$. However, there were more boys who were unacceptable reporters (63.5\%) compared to girls (57.5\%). More children in the age group of 10-12 years were unacceptable reporters $(63.3 \%)$ than children in the age group of 6-9 years $(57.8 \%)$. There were also more

Table 1. Characteristics differences between acceptable reporters $(n=1955)$ and unacceptable reporters $(n=2955)$ who were breakfast consumers.

\begin{tabular}{|c|c|c|c|c|}
\hline & $\begin{array}{c}\text { Acceptable } \\
\text { reporters }\end{array}$ & $\begin{array}{c}\text { Unacceptable } \\
\text { reporters }\end{array}$ & & $p-$ \\
\hline Characteristics & $n(\%)$ & $n(\%)$ & $x^{2}$ & value \\
\hline Area & & & 0.72 & 0.732 \\
\hline Urban & $1330(40.0)$ & $1996(60.0)$ & & \\
\hline Rural & $625(39.5)$ & $959(60.5)$ & & \\
\hline Sex & & & 18.46 & 0.000 \\
\hline Boys & 809 (36.5) & $1407(63.5)$ & & \\
\hline Girls & $1146(42.5)$ & $1548(57.5)$ & & \\
\hline Age groups & & & 15.29 & 0.000 \\
\hline $6-9$ years & $1171(42.2)$ & $1603(57.8)$ & & \\
\hline $10-12$ years & $784(36.7)$ & $1352(63.3)$ & & \\
\hline Ethnic groups & & & 30.17 & 0.000 \\
\hline Malay & 1334 (41.9) & $1847(58.1)$ & & \\
\hline Chinese & $263(32.1)$ & $557(67.9)$ & & \\
\hline Indian & $130(35.6)$ & $235(64.4)$ & & \\
\hline $\begin{array}{l}\text { Bumiputera Sabah/ } \\
\text { Sarawak }\end{array}$ & $228(41.9)$ & $316(58.1)$ & & \\
\hline Income group (MYR) & & & 4.00 & 0.136 \\
\hline Low $(<1500)$ & $629(40.9)$ & 908 (59.1) & & \\
\hline Middle (1501-7500) & $1058(38.7)$ & $1676(61.3)$ & & \\
\hline High $(>7500)$ & $217(42.7)$ & 291 (57.3) & & \\
\hline $\begin{array}{l}\text { Father's education } \\
\text { level }\end{array}$ & & & 1.87 & 0.172 \\
\hline $\begin{array}{l}\text { Secondary and } \\
\text { below }\end{array}$ & 1155 (39.1) & 1797 (60.9) & & \\
\hline Tertiary & $701(41.2)$ & 1002 (58.8) & & \\
\hline $\begin{array}{l}\text { Mother's education } \\
\text { level }\end{array}$ & & & 0.53 & 0.477 \\
\hline $\begin{array}{l}\text { Secondary and } \\
\text { below }\end{array}$ & $1196(39.4)$ & $1836(60.6)$ & & \\
\hline Tertiary & $691(40.5)$ & $1014(59.5)$ & & \\
\hline RTEC consumption & & & 4.08 & 0.045 \\
\hline RTEC consumers & $347(43.0)$ & $460(57.0)$ & & \\
\hline $\begin{array}{l}\text { Non-RTEC } \\
\text { consumers }\end{array}$ & $1608(39.2)$ & $2496(60.8)$ & & \\
\hline
\end{tabular}

non-RTEC consumers who were unaccaptable reporters $(60.8 \%)$ than RTEC consumers (57.0\%).

Among the children, $17.7 \%$ consumed an RTEC at breakfast. Almost all of the children (99.9\%) consumed flaked or puffed types of RTEC. All of these RTEC were fortified with $B$ vitamins and iron, and some of them with calcium, vitamin $\mathrm{A}$ and vitamin $\mathrm{C}$ as well. The mean intake of RTEC was $23.8 \mathrm{~g} /$ day $(S D=20.1)$ for the total sample of cosumers. Among 6-9 year olds, the mean intake of RTEC was $21.3 \mathrm{~g} /$ day $(S D=14.9)$, while among 10-12 year olds, the mean intake was $28.7 \mathrm{~g} /$ day $(S D=27.2)$. A greater percentage of RTEC consumers were from urban areas $(73.8 \%)$ compared to non-consumers $(66.8 \%)(p=0.014)$. There was a greater proportion of Indian children consuming a RTEC breakfast (13.0\%) than non-RTEC (5.3\%) breakfast $(p<0.001)$. Among RTEC consumers, there were more children in the younger age group (6-9 years) $(p=0.006)$, from higher income groups, and from families with parents who had tertiary level education compared to other breakfast consumers $(p<0.001)$. There was no significant difference in bodyweight status among RTEC consumers and non-RTEC consumers (Table 2).

Table 3 outlines the top 10 food and beverage items consumed at breakfast by RTEC consumers and nonRTEC consumers. Overall, in the total sample of Malaysian children, the most common breakfast items reported were malted beverages (64.4\%), bread (40.9\%), condensed milk (37.3\%), sugar and preserves (34.1\%), eggs (29.2\%) and nasi lemak (21.2\%). Among RTEC consumers, malted beverages, ultra-heat treated (UHT) milk, condensed milk, bread and powdered milk were the most common items reported as being consumed. Malted beverages, bread, condensed milk, sugar and preserves, eggs and nasi lemak were the most common breakfast items consumed by non-RTEC consumers (Table 3).

In Table 4, nutrient intakes at breakfast and for the whole day are compared between RTEC consumers and non-RTEC consumers. With regards to macronutrient intakes, RTEC consumers had a significantly higher percentage of energy from carbohydrate than non-RTEC consumers both at breakfast $(57.7 \%$ versus $55.1 \% ; p<0.001)$ and for the total day $(50.3 \%$ versus $49.2 \%$; $p=0.011)$. RTEC consumers also had a significantly lower energy contribution from fat at breakfast (29.6\% versus $33.6 \% ; p<0.001)$ and this difference remained statistically signficant for daily intakes ( $p=0.048)$, while there was no significant difference in protein intakes at breakfast or for the total day. Sodium intakes at breakfast (391 $\mathrm{mg}$ versus $574 \mathrm{mg}$ ) and for the total day (1901 mg versus $2038 \mathrm{mg}$ ) were 
Table 2. Socio-demographic characteristics of RTEC and nonRTEC consumers $(n=1955)$.

\begin{tabular}{|c|c|c|c|c|c|}
\hline \multirow[b]{3}{*}{ Variable } & \multirow{3}{*}{$\begin{array}{c}\text { Total, } \\
n\end{array}$} & \multicolumn{2}{|c|}{ Breakfast choice groups } & \multirow[b]{3}{*}{$x^{2}$} & \multirow{3}{*}{$\begin{array}{c}p- \\
\text { value }\end{array}$} \\
\hline & & $\begin{array}{c}\text { RTEC } \\
\text { consumers }\end{array}$ & $\begin{array}{l}\text { Non-RTEC } \\
\text { consumers }\end{array}$ & & \\
\hline & & $n(\%)$ & $n(\%)$ & & \\
\hline Overall & 1955 & $347(17.7)$ & $1608(82.3)$ & & \\
\hline Regions & & & & 16.68 & 0.002 \\
\hline Central & 348 & 69 (19.9) & $279(17.4)$ & & \\
\hline Southern & 343 & $83(23.9)$ & $260(16.2)$ & & \\
\hline Northern & 541 & $88(25.4)$ & $453(28.2)$ & & \\
\hline East Coast & 368 & $50(14.4)$ & $318(19.8)$ & & \\
\hline East Malaysia & 355 & 57 (16.4) & $298(18.5)$ & & \\
\hline Area & & & & 6.08 & 0.014 \\
\hline Urban & 1330 & $256(73.8)$ & $1074(66.8)$ & & \\
\hline Rural & 625 & $91(26.2)$ & $534(33.2)$ & & \\
\hline Sex & & & & 0.73 & 0.394 \\
\hline Boys & 809 & $136(39.2)$ & $673(41.9)$ & & \\
\hline Girls & 1146 & $211(60.8)$ & $935(58.1)$ & & \\
\hline Age groups & & & & 7.49 & 0.006 \\
\hline $6-9$ years & 1171 & $231(66.6)$ & $940(58.5)$ & & \\
\hline $10-12$ years & 784 & $116(33.4)$ & $668(41.5)$ & & \\
\hline Ethnic groups & & & & 29.89 & $<0.001$ \\
\hline Malay & 1334 & $229(66.0)$ & $1105(68.7)$ & & \\
\hline Chinese & 263 & $34(9.8)$ & 229 (14.2) & & \\
\hline Indian & 130 & $45(13.0)$ & $85(5.3)$ & & \\
\hline $\begin{array}{l}\text { Bumiputera Sabah/ } \\
\text { Sarawak }\end{array}$ & 228 & $39(11.2)$ & 189 (11.8) & & \\
\hline $\begin{array}{l}\text { Income groups } \\
\qquad\left(M^{\prime} R^{+}\right)(n=1905)\end{array}$ & & & & 17.21 & $<0.001$ \\
\hline Low $(<1500)$ & 629 & $81(23.8)$ & $548(35.0)$ & & \\
\hline Middle (1501-7500) & 1058 & $209(61.5)$ & $849(54.3)$ & & \\
\hline High $(>7500)$ & 217 & $50(14.7)$ & $167(10.7)$ & & \\
\hline $\begin{array}{l}\text { Father's education } \\
\text { level }^{\ddagger}(n=1856)\end{array}$ & & & & 12.13 & $<0.001$ \\
\hline $\begin{array}{l}\text { Secondary and } \\
\text { below }\end{array}$ & 1155 & $180(53.7)$ & $975(64.1)$ & & \\
\hline Tertiary & 701 & $155(46.3)$ & $546(35.9)$ & & \\
\hline $\begin{array}{l}\text { Mother's education } \\
\text { level }^{\ddagger}(n=1887)\end{array}$ & & & & 11.60 & 0.001 \\
\hline $\begin{array}{l}\text { Secondary and } \\
\text { below }\end{array}$ & 1196 & $187(55.2)$ & $1009(65.2)$ & & \\
\hline Tertiary & 691 & $152(44.8)$ & $539(34.8)$ & & \\
\hline Bodyweight status ${ }^{\S}$ & & & & 2.14 & 0.544 \\
\hline $\begin{array}{l}\text { Severely thin and } \\
\text { thin }\end{array}$ & 186 & $39(11.2)$ & $147(9.1)$ & & \\
\hline Normal & 1481 & $253(72.9)$ & $1228(76.4)$ & & \\
\hline Overweight & 166 & $32(9.2)$ & $134(8.3)$ & & \\
\hline Obese & 122 & $23(6.6)$ & $99(6.2)$ & & \\
\hline
\end{tabular}

${ }^{\dagger}$ MYR - Malaysian Ringgit

${ }^{\text {F}}$ Secondary and below: receieved $\leq 12$ years of formal education; Tertiary: receieved $>12$ years of formal education

${ }^{\S}$ Based on BMI-for-age z-scores: Severely thin and thin (z-score<-2SD); Normal $(-2 S D \leq z$-score $\leq+1 S D)$; Overweight $(+1 S D<z$-Score $\leq+2 S D)$ and obese $(\mathrm{z}$-score $>+2 \mathrm{SD})$

lower in RTEC consumer than non-RTEC consumers $(p<0.001)$. RTEC consumers had higher intakes of vitamin $\mathrm{C}$, thiamin, riboflavin, niacin, calcium and iron both at breakfast and throughout the day than nonRTEC consumers $(p<0.001)$. Mean intakes of vitamin $A$ and phosphorus were significantly higher in nonRTEC consumers at breakfast $(p<0.01)$ but there was no difference in daily intakes. RTEC consumers had higher intake of sugar daily and at breakfast than nonRTEC consumers (Table 4).
Breakfast contributed to a similar proportion of daily energy intakes in both RTEC (24.5\%) and nonRTEC $(26.3 \%)$ consumers. Non-RTEC consumers had a higher percentage of daily fat from breakfast $(26.5 \%)$ than RTEC consumers (22.4\%). Breakfast contributed to $30-50 \%$ of daily intakes of vitamin C, riboflavin, niacin, calcium and iron in RTEC consumers whereas it contributed $25-38 \%$ to intakes of these nutrients in non-RTEC consumers. Among RTEC consumers, RTEC alone contributed only $5 \%$ to daily energy intakes but contributed up to $25.8 \%$ of the daily intake for thiamin, $22.1 \%$ for vitamin C, $21.6 \%$ for niacin, $21.2 \%$ for riboflavin, $14.9 \%$ for iron and $10.0 \%$ for calcium (Figure 1).

The prevalence of children not meeting at least $80 \%$ of the RNI for vitamin C, thiamin, riboflavin, niacin and calcium were significantly higher among nonRTEC than RTEC consumers, and in both types of consumers the prevalence was higher among children in the older age group (10-12 years) than children in the younger age group (6-9 years) (Table 5). Notably approximately two thirds of all children did not meet the at least $80 \%$ of the RNI for calcium. Among 6-9year-old boys and girls, $45.3 \%$ and $55.2 \%$ of non-RTEC consumers did not achieve at least $80 \%$ of the RNI for calcium respectively, while the prevalence was $18.9 \%$ and $27.7 \%$ among male and female RTEC consumers respectively. In the older children (10-12 years) $80 \%$ of boys and $87.5 \%$ of girls who were non consumers of RTEC did not achieve at least $80 \%$ of the RNI while the corresponding percentages in RTEC consumers was 54 . $\%$ and $70 \%$ respectively.

\section{Discussion}

This is the first nationwide study on the comparison of breakfast choice, specifically between an RTEC and non-RTEC based breakfast among primary school children in Malaysia. Overall, 18\% of children consumed an RTEC at breakfast, the prevalence of which was positively associated with a younger age, Indian ethnicity, urban area of residence, and higher income and education level of parents. Compared to non-RTEC consumers, RTEC consumers had higher intakes of several important nutrients at breakfast including calcium, iron, vitamin $\mathrm{C}$, thiamin, riboflavin and niacin and higher daily intakes and adequacy of many of these nutrients.

The association of RTEC consumption in Malaysia with urban areas, income and education level is likely due to several interrelated factors including the greater availability of RTEC in urban areas and the generally 
Table 3. List of top 10 most frequently consumed food items at breakfast by all the children, RTEC consumers and non-RTEC consumers.

\begin{tabular}{|c|c|c|c|c|c|c|c|c|}
\hline $\begin{array}{l}\text { All children } \\
(n=1955)\end{array}$ & $\%$ & Mean $\pm \mathrm{SD}^{\dagger}$ & $\begin{array}{l}\text { RTEC consumers } \\
(n=347)\end{array}$ & $\%$ & Mean $\pm S D^{\dagger}$ & Non-RTEC consumers $(n=1608)$ & $\%$ & Mean $\pm S^{\dagger}$ \\
\hline Malted beverage & 64.4 & $20.4 \pm 23.3$ & RTEC & 100.0 & $23.8 \pm 20.1$ & Malted beverage & 64.1 & $20.6 \pm 24.0$ \\
\hline Bread & 40.9 & $40.1 \pm 32.6$ & Malted beverage & 65.7 & $19.7 \pm 20.2$ & Bread & 44.2 & $40.8 \pm 33.6$ \\
\hline Condensed milk & 37.3 & $10.7 \pm 9.1$ & UHT milk & 56.5 & $117.5 \pm 68.2$ & Condensed milk & 36.7 & $10.7 \pm 9.3$ \\
\hline Sugar and preserves & 34.1 & $9.1 \pm 15.3$ & Condensed milk & 39.8 & $10.7 \pm 8.6$ & Sugar and preserves & 36.7 & $9.4 \pm 16.2$ \\
\hline Eggs & 29.2 & $29.3 \pm 23.8$ & Bread & 25.6 & $34.5 \pm 23.1$ & Eggs & 31.8 & $29.4 \pm 24.9$ \\
\hline Nasi lemak ${ }^{\ddagger}$ & 21.2 & $102.7 \pm 47.1$ & Powdered milk & 25.1 & $33.0 \pm 40.9$ & Nasi lemak & 23.9 & $102.6 \pm 47.6$ \\
\hline Tea/coffee & 20.7 & $106.1 \pm 81.1$ & Sugar and preserves & 22.2 & $6.7 \pm 4.4$ & Tea/coffee & 22.4 & $103.6 \pm 82.6$ \\
\hline Chicken and meat & 20.2 & $55.3 \pm 38.2$ & Eggs & 17.3 & $28.5 \pm 10.4$ & Fried rice & 21.6 & $138.4 \pm 78.2$ \\
\hline Fried rice & 19.3 & $137.8 \pm 77.5$ & Chicken and meat & 14.7 & $46.1 \pm 33.4$ & Chicken and meat & 21.4 & $56.7 \pm 38.7$ \\
\hline RTEC & 17.7 & $23.8 \pm 20.1$ & Unleavened bread & 14.1 & $58.4 \pm 29.6$ & Processed fish & 19.7 & $14.1 \pm 16.1$ \\
\hline
\end{tabular}

${ }^{\dagger}$ All measurement units are in grams $(\mathrm{g})$, except for tea/coffee and UHT milk, which are in mililitres (ml)

${ }^{\ddagger}$ Nasi lemak - rice cooked in coconut milk.

Table 4. Comparison of nutrient intakes between RTEC and non-RTEC consumers $(n=1819)$.

\begin{tabular}{|c|c|c|c|c|c|c|c|c|}
\hline \multirow[b]{2}{*}{ Nutrient } & \multicolumn{3}{|c|}{ RTEC consumers $(n=331)$} & \multicolumn{3}{|c|}{ Non-RTEC consumers $(n=1488)$} & \multirow[b]{2}{*}{$\underset{\mathrm{a}}{\text { value }^{-}}$} & \multirow[b]{2}{*}{$\underset{b}{p-}$} \\
\hline & $\begin{array}{l}\text { Breakfast } \\
\text { intake } \\
\text { (Mean } \pm S D)\end{array}$ & $\begin{array}{l}\text { Daily intake } \\
\text { (Mean } \pm S D)\end{array}$ & $\begin{array}{c}\text { Breakfast intake as a \% } \\
\text { of daily intake } \\
(\%)\end{array}$ & $\begin{array}{l}\text { Breakfast } \\
\text { intake } \\
\text { (Mean } \pm S D)\end{array}$ & $\begin{array}{l}\text { Daily intake } \\
\text { (Mean } \pm S D)\end{array}$ & $\begin{array}{c}\text { Breakfast intake as a \% } \\
\text { of daily intake } \\
(\%)\end{array}$ & & \\
\hline Energy, kcal & $441 \pm 186$ & $1816 \pm 314$ & 24.5 & $466 \pm 197$ & $1794 \pm 312$ & 26.3 & 0.502 & 0.063 \\
\hline Protein, $\mathrm{g}$ & $14.9 \pm 7.9$ & $81.1 \pm 26.1$ & 19.3 & $15.7 \pm 8.2$ & $79.8 \pm 23.8$ & 20.8 & 0.696 & 0.746 \\
\hline $\begin{array}{l}\% \text { Energy from } \\
\text { protein }\end{array}$ & $13.5 \pm 3.8$ & $17.9 \pm 4.7$ & & $13.4 \pm 4.1$ & $17.8 \pm 4.3$ & & 0.916 & 0.768 \\
\hline Carbohydrate, g & $61.8 \pm 23.2$ & $228.0 \pm 49.1$ & 27.6 & $62.3 \pm 25.4$ & $220.5 \pm 47.6$ & 28.8 & 0.005 & 0.005 \\
\hline $\begin{array}{l}\text { \% Energy from } \\
\text { carbohydrate }\end{array}$ & $57.7 \pm 10.0$ & $50.3 \pm 7.3$ & & $55.1 \pm 12.0$ & $49.2 \pm 7.4$ & & $<0.001$ & 0.011 \\
\hline Fat, $\mathrm{g}$ & $14.8 \pm 8.1$ & $68.2 \pm 17.6$ & 22.4 & $17.8 \pm 9.5$ & $68.7 \pm 17.7$ & 26.5 & $<0.001$ & 0.017 \\
\hline $\begin{array}{l}\% \text { Energy from } \\
\text { fat }\end{array}$ & $29.6 \pm 8.7$ & $33.7 \pm 5.7$ & & $33.6 \pm 10.6$ & $34.4 \pm 5.8$ & & $<0.001$ & 0.048 \\
\hline Total Sugar, $\mathrm{g}^{\ddagger}$ & $17.1 \pm 15.6$ & $41.7 \pm 21.8$ & 47.1 & $9.5 \pm 8.8$ & $32.5 \pm 20.9$ & 34.2 & $\leq 0.001$ & $\leq 0.001$ \\
\hline Vitamin A, mg RE & $156.9 \pm 161.5$ & $1026.2 \pm 432.6$ & 16.9 & $222.7 \pm 219.7$ & $1011.7 \pm 441.8$ & 23.3 & $<0.001$ & 0.429 \\
\hline Vitamin C, mg & $21.2 \pm 11.5$ & $72.6 \pm 43.7$ & 36.7 & $10.4 \pm 9.1$ & $54.2 \pm 39.8$ & 25.0 & $<0.001$ & $<0.001$ \\
\hline Thiamin, mg & $0.6 \pm 0.3$ & $1.2 \pm 0.5$ & 50.2 & $0.3 \pm 0.2$ & $0.9 \pm 0.4$ & 38.1 & $<0.001$ & $<0.001$ \\
\hline Riboflavin, mg & $0.8 \pm 0.4$ & $1.7 \pm 0.6$ & 48.0 & $0.4 \pm 0.2$ & $1.3 \pm 0.5$ & 34.2 & $<0.001$ & $<0.001$ \\
\hline Niacin, mg & $6.7 \pm 3.3$ & $16.2 \pm 4.9$ & 41.9 & $4.0 \pm 2.4$ & $13.4 \pm 4.7$ & 30.6 & $<0.001$ & $<0.001$ \\
\hline Sodium, mg & $390.5 \pm 305.2$ & $1901.1 \pm 734.5$ & 21.3 & $573.7 \pm 395.9$ & $2037.8 \pm 751.9$ & 29.1 & $<0.001$ & $<0.001$ \\
\hline Calcium, mg & $315.0 \pm 159.1$ & $741.9 \pm 254.4$ & 43.4 & $192.5 \pm 109.2$ & $586.2 \pm 225.2$ & 34.1 & $<0.001$ & $<0.001$ \\
\hline Iron, mg & $6.4 \pm 3.1$ & $20.1 \pm 6.6$ & 33.3 & $6.2 \pm 4.7$ & $19.2 \pm 7.3$ & 32.6 & 0.007 & 0.013 \\
\hline Phosphorus, mg & $214.6 \pm 156.8$ & $1239.6 \pm 453.5$ & 18.6 & $251.6 \pm 158.1$ & $1240.8 \pm 440.6$ & 21.9 & 0.002 & 0.527 \\
\hline
\end{tabular}

higher levels of income and education among urban dwellers compared to rural dwellers. The mean household income of Malaysians in urban and rural areas was MYR6833 and MYR3831 (USD1748 and USD980) per month respectively in 2014.[19] Furthermore, the modernization and nutrition transition that occur more rapidly in the urban areas might have slowly changed the dietary habits of children from consumption of traditional breakfast foods that require cooking to ready-to-eat foods that require minimal preparation. In a study which investigated breakfast consumption, specifically RTEC consumption in an urban sample of 382 children aged 10-11 years from Kuala Lumpur, it was found that as many as $93 \%$ of children reported consumption of RTEC at least once per week and almost half consumed them two to three times per week.[20] In this mainly middle income urban sample, the higher cost of RTEC did not appear to be a barrier to consumption. Among the most cited reasons by parents for purchasing RTECs were health, taste, enhanced satiety and short preparation time.[20]

The findings that children who consume RTEC at breakfast have higher intakes of several nutrients throughout the day than those not consuming RTEC is in agreement with several other studies from around the world. A recent review on the benefits of breakfast cereal consumption revealed that out of 30 cross sectional studies conducted in seven countries (USA, Australia, UK, France, Greece, Spain and Iceland), the majority reported a higher daily intake of carbohydrate (as a percentage of daily energy), fibre, total sugars, vitamin $\mathrm{A}$, vitamins $\mathrm{B} 1, \mathrm{~B} 2, \mathrm{~B} 3, \mathrm{~B} 6$ and folate, vitamin 


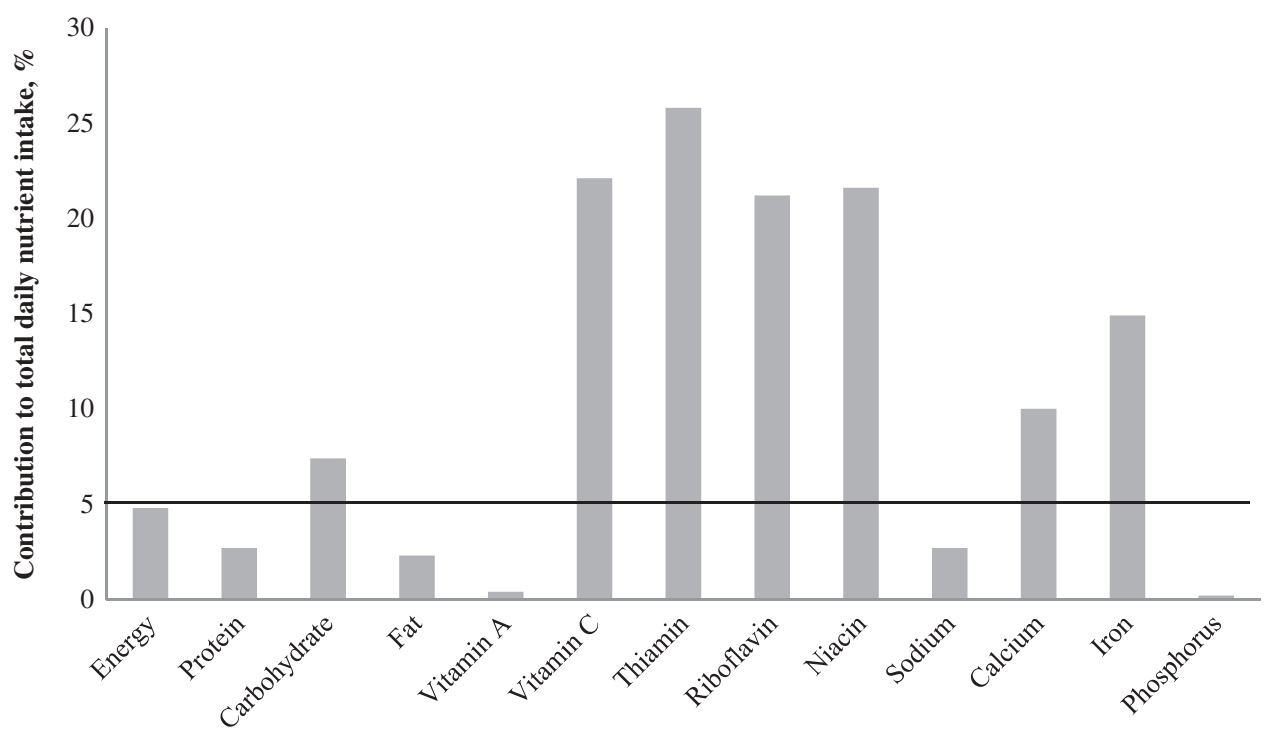

Figure 1. Percentage contribution of RTEC to total daily nutrient intake among RTEC consumers $(n=347)$.

Table 5. Distribution of RNI achievements among RTEC and non-RTEC consumers according to gender.

\begin{tabular}{|c|c|c|c|c|c|c|c|c|c|c|}
\hline \multirow[b]{4}{*}{ Variables } & \multicolumn{3}{|c|}{ Boys } & \multirow[b]{4}{*}{$x^{2}$} & \multirow[b]{4}{*}{$\begin{array}{c}p- \\
\text { value }\end{array}$} & \multicolumn{5}{|c|}{ Girls } \\
\hline & \multirow[t]{3}{*}{$\mathbf{R N I}^{\dagger}$} & RTEC consumers & $\begin{array}{l}\text { Non-RTEC } \\
\text { consumers }\end{array}$ & & & $\mathrm{RNI}$ & RTEC consumers & $\begin{array}{l}\text { Non-RTEC } \\
\text { consumers }\end{array}$ & \multirow[b]{3}{*}{$x^{2}$} & \multirow[b]{3}{*}{$\begin{array}{c}p- \\
\text { value }\end{array}$} \\
\hline & & $\begin{array}{l}\text { RNI achievement, } n \\
(\%)\end{array}$ & $\begin{array}{l}\text { RNI achievement, } n \\
(\%)\end{array}$ & & & & $\begin{array}{l}\text { RNI achievement, } n \\
(\%)\end{array}$ & $\begin{array}{l}\text { RNI achievement, } n \\
(\%)\end{array}$ & & \\
\hline & & $<80$ & $<80$ & & & & $<80$ & $<80$ & & \\
\hline \multicolumn{11}{|l|}{$\begin{array}{l}\text { Vitamin } A, ~ m g \\
R E\end{array}$} \\
\hline 6-9 years & 500 & $1(1.1)$ & $29(7.3)$ & 4.87 & 0.027 & 500 & $13(9.2)$ & $34(6.3)$ & 1.53 & 0.216 \\
\hline $10-12$ years & 600 & $3(6.5)$ & 32 (11.6) & 1.05 & 0.306 & 600 & $5(7.1)$ & $50(12.8)$ & 1.78 & 0.182 \\
\hline \multicolumn{11}{|l|}{ Vitamin C, mg } \\
\hline $6-9$ years & 35 & $11(12.2)$ & $109(27.5)$ & 9.17 & 0.002 & 35 & $12(8.5)$ & $162(29.8)$ & 26.83 & $<0.001$ \\
\hline $10-12$ years & 65 & $15(32.6)$ & $157(56.9)$ & 9.34 & 0.002 & 65 & $32(45.7)$ & $226(57.7)$ & 3.43 & 0.064 \\
\hline \multicolumn{11}{|l|}{ Thiamin, mg } \\
\hline 6-9 years old & 0.9 & $10(11.1)$ & $131(33.0)$ & 17.09 & $<0.001$ & 0.9 & $14(9.9)$ & $217(40.0)$ & 45.14 & $<0.001$ \\
\hline $10-12$ years & 1.2 & 8 (17.4) & $166(60.1)$ & 29.02 & $<0.001$ & 1.1 & $24(34.3)$ & $224(42.9)$ & 12.48 & $<0.001$ \\
\hline \multicolumn{11}{|l|}{ Riboflavin, mg } \\
\hline 6-9 years & 0.9 & $0(0.0)$ & $19(4.8)$ & 4.48 & 0.034 & 0.9 & $0(0.0)$ & $40(7.4)$ & 11.03 & $<0.001$ \\
\hline $10-12$ years & 1.3 & $3(6.5)$ & $91(33.0)$ & 13.34 & $<0.001$ & 1.0 & $5(7.1)$ & $60(15.3)$ & 3.27 & 0.070 \\
\hline \multicolumn{11}{|l|}{ Niacin, mg } \\
\hline $6-9$ years & 12 & $3(3.3)$ & 78 (19.6) & 14.08 & $<0.001$ & 12 & 8 (5.7) & $130(23.9)$ & 23.19 & $<0.001$ \\
\hline $10-12$ years & 16 & $5(10.9)$ & $102(37.0)$ & 12.09 & 0.001 & 16 & $22(31.4)$ & $188(48.0)$ & 6.55 & 0.011 \\
\hline \multicolumn{11}{|l|}{ Calcium, mg } \\
\hline $6-9$ years & 700 & $17(18.9)$ & $180(45.3)$ & 21.31 & $<0.001$ & 700 & $39(27.7)$ & $300(55.2)$ & 34.08 & $<0.001$ \\
\hline $10-12$ years & 1000 & $25(54.3)$ & $221(80.1)$ & 14.47 & $<0.001$ & 1000 & $49(70.0)$ & $343(87.5)$ & 14.15 & $<0.001$ \\
\hline \multicolumn{11}{|l|}{ Iron, mg } \\
\hline $6-9$ years & 6 & $0(0.0)$ & $3(0.8)$ & 0.68 & 0.408 & 6 & $0(0.0)$ & $2(0.4)$ & 0.52 & 0.470 \\
\hline $10-12$ years & 10 & $0(0.0)$ & $3(1.1)$ & 0.51 & 0.477 & 9 & $0(0.0)$ & $5(1.3)$ & 0.90 & 0.342 \\
\hline
\end{tabular}

${ }^{\dagger} \mathrm{RNI}$ - Recommended Nutrient Intake (NCCFN, 2005)

$\mathrm{D}$, calcium, iron, magnesium and zinc in children regularly consuming RTEC compared to those consuming them less frequently or not at all.[4] The majority of these studies also reported no differences in daily energy intake, percentage energy from protein and a lower percentage energy from fat in RTEC consumers compared to non-consumers, which concurs with our findings. Furthermore, in line with our results micronutrient adequacy tended to be higher in RTEC consumers compared to non-consumers in several of these studies, especially for calcium.[21-26] Of note, the lowest level of inadequate intake in the current study was for calcium, with about two thirds of all children failing to meet $80 \%$ of the RNI, and this was more prevalent in the older children. The nationwide SEANUTS study also recently highlighted calcium as a 
nutrient of concern in Malaysian children.[27] In the current study, the percentage of children achieving at least $80 \%$ of the RNI for calcium was twice as high in RTEC consumers aged 6-9 years and around 1.5 times higher in RTEC consumers aged 10-12 years compared to non-consumers. Higher consumption of milk in RTEC consumers is a probable factor explaining the higher calcium intakes as $56 \%$ and $25 \%$ of RTEC consumers reporting consumption of UHT and powdered milk respectively compared to only $8.6 \%$ and $12.2 \%$ respectively.

Similar to our findings, another study on Malaysian urban children also reported higher daily intakes of the $B$ vitamins and vitamin C in RTEC consumers. [20] The reasons for higher intakes of these mironutrients in RTEC consumers is likely related to the fortification of these cereals. RTEC alone made a significant contribution to daily micronutrient intakes, providing $10 \%$ to calcium intakes, $15 \%$ to iron intakes, and more than $20 \%$ to intakes of vitamin $\mathrm{C}$, thiamin, riboflavin and niacin, which probably reflects the fortification profile of RTECs in the Malaysian market. Intake of phosphorus, however, was lower among RTEC consumers than non-consumers, which may be because phosphorus is naturally higher in foods such as eggs and meat that were consumed more often by non-RTEC consumers at breakfast. No differences in the daily intakes of phosphorus were noted, suggesting that other meals in the day compensated for the lower intake at breakfast among RTEC consumers. Intake of vitamin A was also lower among RTEC consumers than non-consumers at breakfast. This may be because only some RTEC were fortified with vitamin A, others were not, and vitamin $\mathrm{A}$ is also naturally present in eggs and meat which were consumed more often by non-RTEC consumers than RTEC consumers at breakfast. However, there was also no significant difference in the daily intake of vitamin A among RTEC consumers and non-consumers.

The contribution of RTEC to whole grain intake is another possible factor contributing to higher micronutrient intakes in RTEC consumers. Whole grains retain the three naturally present components of the grain (germ, endosprem and bran) and are therefore generally higher in fibre, vitamins (vitamin E, B vitamins), minerals (iron, copper, zinc, magnesium) and phytochemicals than their refined grain counterparts. [28] A previous analysis of data from the MyBreakfast study showed that RTECs contributed up to $70 \%$ of total whole grain intake in children's diets.[9] It was also shown that foods such as bread, rice and noodles which had a high reported prevalence of consumption at breakfast in the current study amongst non-RTEC consumers contributed less than $2 \%$ to total whole grain intakes. [9] This indicates that almost all of these cereal foods are consumed in their refined version, which possibly will have a negative impact on fibre and some micronutrient intakes in this population group. However, as the Malaysian food composition tables do not contain dietary fibre we were unable estimate intakes in this study. Lastly, it should be noted that RTEC consumers may have a more nutrient dense food choice throughout the rest of day which could account for some of the differences in nutrient intakes observed.

In addition to the low consumption of wholegrain foods at breakafast, food choices in the non-RTEC consumers tended to be energy dense (e.g. nasi lemak and fried rice were consumed by $24 \%$ and $22 \%$ respetively). Other studies in Malaysia have reported the consumption of high fat or high sugar, energy dense foods in preschoolers and adolescents at breakfast including fried rice and noodle dishes [5] and fried traditional cakes as well as biscuits.[6] These food choices are likely to have contributed to the higher fat intakes at breakfast that we observed in non-RTEC consumers and the higher overall contribution of breakfast to daily fat intake compared to RTEC consumers (22\% versus $27 \%$ ). There was also a higher frequency of consumption in foods high in sugar at breakfast including condensed milk and sugar and preserves, however we were unable to accurately measure intakes of total sugars in this sample as the Malaysian food composition tables do not currently include this information. Sugar content can only be obtained from manufacturers' labelling and in Malaysia it is not mandatory to label sugar. Therefore some products may include sugar content in their nutrition information panel, while some do not, and because of the absence of information on sugar content in the Malaysian food composition tables, the sugar content of non-packaged foods could not be obtained. Notwithstanding these limitations, the estimated total sugar intake appeared higher in consumers of RTEC than non-consumers. From the available brand information reported by participants, it was estimated that the sugar content of RTEC ranged from $15 \%$ in cornflakes to $25 \%$ in wheat based cereals. Previous studies have reported higher total sugar intakes in RTEC consumers versus non-consumers [4] but this may be in part be explained by the higher dairy intake associated with RTEC consumption. For example, in the HELENA study of European adolescents, RTEC consumers had higher intakes of total simple sugars at breakfast but with a higher proportion of lactose than sucrose.[29] While RTECs can contribute to increased 
micronutrient intake, efforts must be made to ensure that the sugar content is kept low. While there is a need to maintain consumer palatability of such cereals, efforts can be made to have gradual reduction of sugar over time. Futhermore, it is important that efforts are made in the future to complete the Malaysian food composition tables so that intakes and sources of sugars can be assessed and monitored.

One of the major strengths of this study is the large sample size and the nationwide sampling undertaken. Another strength is that dietary intake data were collected at brand level so that RTEC and other fortified foods in the Malaysain food composition tables could be updated for micronutrient content based on nutrition panels of packaging. The high number of unacceptable energy reporters however ( $60 \%$ of the sample) is a limitation of the study as it may have introduced bias into the final sample. For example, the prevalence of unacceptable energy reporters was higher among children aged 1012 years $(63.2 \%)$ than children aged $6-9$ years $(58.2 \%)$ and among Chinese children (68.9\%) than Malay children (58.2\%). Removal of unacceptable reporters limits the generalizibility of the results to the total populationas as there were more young children and less Chinese children in the sample.

We chose to remove unacceptable reporters to get a more accurate assessment of nutrient intake adequacy as their inclusion could have resulted in an over- or underestimation of nutrient intakes and prevalences of micronutrient inadequacies. As alluded to earlier, another limitation was the lack of nutrients available in the Malaysian food composition tables, especially for nutrients of public health relevance including sugar, fatty acid composition, dietary fibre and vitamin D. Fluctuations of food intakes from day to day may lead to misclassification of participants according to RTEC consumption We estimated average intake over two days of 24-h dietary recalls or records and did not apply a statistical adjustment for usual intakes. Different nutritional assessment methods were used between age groups, though the study attempted to orient the respondent to recall/record the food accurately. Nevertheless, under- and over-reporting occurred.

\section{Conclusion}

This study demonstrates that fortified RTEC are an important source of nutrients (mainly calcium, B vitamins and vitamin $\mathrm{C}$ ) at breakfast and for the total daily diet in Malaysian children and their inclusion in the diet may help children to meet the recommended targets for normal growth and development.
However total sugar intakes appeared to be higher in RTEC consumers. Thus, parents should be encouraged to choose varieties with a lower sugar content. Further work is needed to accurately assess the impact of RTEC consumption on daily sugar intakes and other nutrients of concern including dietary fibre. In addition, future research should attempt to better characterize different types of breakfast foods and the combinations in which they are eaten using dietary pattern analysis and relate these patterns to nutrient and health outcomes.

\section{Acknowledgements}

The MyBreakfast study was funded by Cereal Partners Worldwide (CPW), Lausanne, Switzerland and Nestlé R\&D Center, Singapore. We wish to thank the research assistants, Nur Amalina Dzukarnain, Nur Zalika Zamzuri, Farah Wahida Za'abar and Rozahidah Roslee for their contribution in the data collection. We also recognize the invaluable contributions from all schools, parents and students who participated in the MyBreakfast study conducted by the Nutrition Society of Malaysia.

\section{Disclosure statement}

No potential conflict of interest was reported by the authors.

\section{Funding}

This work was supported by the Cereal Partners Worldwide (CPW), Lausanne, Switzerland; Nestlé R\&D Center, Singapore.

\section{References}

[1] Rampersaud GC, Pereira MA, Girard BL, et al. Breakfast habits, nutritional status, body weight, and academic performance in children and adolescents. J Am Diet Assoc. 2005;105:743-760.

[2] Blondin SA, Anzman-Frasca S, Djang HC, et al. Breakfast consumption and adiposity among children and adolescents: an updated review of the literature review. Pediatr Obes. 2016;11:333-348.

[3] Suraiami M, Mohd Fairulnizal MN, Norhayati MK, et al. Nutritional composition of ready-to-eat cereals in the Malaysian market. Malays J Nutr. 2014;20(3):417-427.

[4] Williams PG. The benefits of breakfast cereal consumption: A systematic review of the evidence base. Adv Nutr. 2014;5:636S-673S.

[5] Norimah AK, Mohd Nasir MT, Haziz AS, et al. Association of body weight status and socio-demographic factors with food habits among preschool children in Peninsular Malaysia. Malays J Nutr. 2014;20 (3):303-315.

[6] Nurul-Fadhilah A, Teo PS, Huybrechts I, et al. Infrequent breakfast consumption is associated with 
higher body adiposity and abdominal obesity in Malaysian school-aged adolescents. PLoS One. 2013;8 (3):e59297.

[7] Foo LH, Khor GL, Tee ES, et al. Dietary intake of adolescents in a rural fishing community in Tuaran district, Sabah. Malays J Nutr. 2006;12(1):11-21.

[8] Department of Statistics Malaysia. Preliminary count report: population and Housing Census of Malaysia 2010. Putrajaya: Department of Statistics Malaysia; 2010.

[9] Norimah AK, Koo HC, Hamid JM, et al. Whole grain intakes in the diets of Malaysian children and adolescents - findings from the MyBreakfast Study. Plos One. 2015;10(10):e0138247.

[10] Jan Mohamed HJ, Loy SL, Mohd Taib MN, et al. Characteristics associated with the consumption of malted beverages among Malaysian primary school children: findings from the MyBreakfast study. BMC Public Health. 2015;15:1322.

[11] WHO. WHO AnthroPlus for personal computers manual: software for assessing growth of the world's children and adolescents. Geneva: World Health Organization; 2009.

[12] De Onis M, Onyango AW, Borghi E, et al. Development of a WHO growth reference for school-aged children and adolescents. Bull World Health Organ. 2007;85:660-667.

[13] Tee ES, Mohd Ismail N, Mohd Nasir A, et al. Nutrient composition of malaysian foods. 4th ed. Malaysian Food Composition Database Programme. Kuala Lumpur: Institute for Medical Research; 1997.

[14] NCCFN, National Coordinating Committee on Food and Nutrition. Recommended nutrient intakes for Malaysia. Putrajaya: National Coordinating Committee on Food and Nutrition, Ministry of Health Malaysia; 2005.

[15] FAO/WHO/UNU. Expert consultation on energy and protein requirements. Geneva: World Health Organization; 1985. (WHO Technical Report Series No. 724).

[16] Poh BK, Ismail M, Zawiah $\mathrm{H}$, et al. Predictive equations for the estimation of basal metabolic rate in Malaysia adolescents. Malays J Nutr. 1999;5(1):1-14.

[17] Poh BK, Ismail MN, Ong HF, et al. BMR predictive equations for Malaysian adolescents aged 12-18 years. Kuala Lumpur: Faculty of Allied Health Sciences, Universiti Kebangsaan Malaysia; 2004. (Final Report for IRPA 06-02-02-0096 Research Project).
[18] Torun B, Davies PSW, Livingstone MBE, et al. Energy requirements and dietary energy recommendations for children and adolescents 1 to 18 years old. Eur J Clin Nutr. 1996;50(Suppl 1):S37-S81.

[19] Department of Statistics Malaysia. Report of household income and basic amenities survey 2014. Putrajaya: Department of Statistics Malaysia; 2015.

[20] Koo H-C, Abdul Jalil SN, Ruzita AT. Breakfast eating pattern and ready-to-eat cereals consumption among schoolchildren in Kuala Lumpur. Malays J Med Sci. 2015;22(1):32-39.

[21] Barr SI, DiFrancesco L, Fulgoni V III. Consumption of breakfast and the type of breakfast consumed are positively associated with nutrient intakes and adequacy of Canadian adults. J Nutr. 2013;143:86-92.

[22] Gibson SA. Iron intake and iron status of preschool children: associations with breakfast cereals, vitamin C and meat. Public Health Nutr. 1999;2:521-528.

[23] Nicklas TA, O’Neil C, Berenson G. Nutrient contribution of breakfast, secular trends, and the role of ready-to-eat cereals: a review of data from the Bogalusa Heart Study. Am J Clin Nutr. 1998;67 (Suppl4):757S-63S.

[24] McNulty H, Eaton-Evans J, Cran G, et al. Nutrient intakes and impact of fortified breakfast cereals in schoolchildren. Arch Dis Child. 1996;75:474-481.

[25] Gibson SA, O'Sullivan K. Breakfast cereal consumption patterns and nutrient intakes of British schoolchildren. J R Soc Health. 1995;115:366-370.

[26] Crawley $H$. The role of breakfast cereals in the diets of 16-17-year-old teenagers in Britain. J Hum Nutr Diet. 1993;6:205-216.

[27] Poh BK, Ng BK, Siti Haslinda MD, et al. Nutritional status and dietary intakes of children aged 6 months to 12 years: findings of the Nutrition Survey of Malaysian Children (SEANUTS Malaysia). Br J Nutr. 2013;110 Suppl 3:SS21-S35.

[28] Slavin J. Whole grains and human health. Nutr Res Rev. 2004;17:99-110.

[29] Michels N, De Henauw S, Beghin L, et al. Ready-to-eat cereals improve nutrient, milk and fruit intake at breakfast in European adolescents. Eur J Nutr. 2015;55:771-779. 